\title{
Setting the problem of designing monitoring systems for engineering structures and methods of its solution
}

\author{
Svetlana Shendiapina ${ }^{1, *}$ and Ramidin Alisultanov ${ }^{1}$ \\ ${ }^{1}$ Moscow State University of Civil Engineering, 26, Yaroslavskoye Shosse, 109377, Moscow, Russia
}

\begin{abstract}
The unprecedented construction of large-span, high-rise and technically complex Olympic facilities in a very short time sets the goal of ensuring the engineering safety of the facilities being built. A necessary condition for its solution is a well-functioning system of continuous monitoring the state of load-bearing structures. It should be capable of identifying unacceptable deviations in the operability of the structure (reducing its reliability) and notifying operating services in a timely manner. The research is devoted to designing such systems. The research subject of the study is a set of requirements for monitoring systems for engineering structures. The feed data for the conducted studies was information about accidents that occurred at constructional projects with various purposes. Analysis of monitoring tools and controlled parameters was used as a research method. The paper investigated some of the existing monitoring systems. The following global monitoring tasks are formulated: what to control; how to control; controlled parameters.
\end{abstract}

\section{Introduction}

On the one hand, modern construction is characterized by a steady increase in the complexity of structures, giving them non-traditional architectural forms and planning solutions, erecting more and more developed buildings in terms of plan and height, improvement of internal environment. On the other hand, it is characterized by increasing requirements for savings, in particular, for reducing material consumption and improving the thermal-mechanical parameters of building envelopes. This is true with all significant construction projects. However, it is especially relevant regarding the construction of largespan or high-rise structures with unique design features.

In a certain sense, this is a contradiction. Sorting it out is possible only with a more thorough study of the engineering-geological conditions of the construction site, the use of advanced materials and technologies, the implementation of complex mathematical calculations, experiments on analog models and full-scale studies.

The Sydney Opera House, which is a prime example of such a unique building project, is shown in Figure 1.

\footnotetext{
* Corresponding author: ShendyapinaSV@mgsu.ru
} 


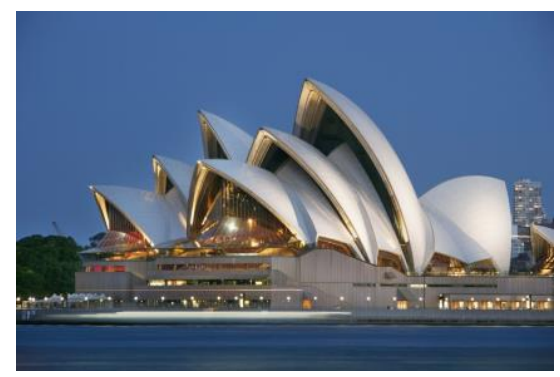

Fig. 1. Sydney Opera House, Australia.

At the same time, quality assurance of the work performed remained unchanged. This is geo-inspection for engineering-geological surveys, expert evaluation for design solutions, engine and construction design supervision for work performed on a construction site, visual inspection by operating services with instrumental surveys conducted at intervals of three to five years at the operation stage, carried out by professional prospectors. There is nothing new in terms of control. However, a new concept appeared, a so-called monitoring of building structures. Monitoring, unfortunately, is sometimes understood as selective instrumental examination of visible parts of building structures with fixation of detected defects. The monitoring of the TRANSVAAL water park at the Baumansky market (Fig. 2, 3), of the "L" chain, the support of the indoor speed skating center in Krylatskoye, Moscow, carried out according to this principle, however, as well as many others not so wide lighted would show that the structures are in good or operational condition, so accidents would not have been prevented.
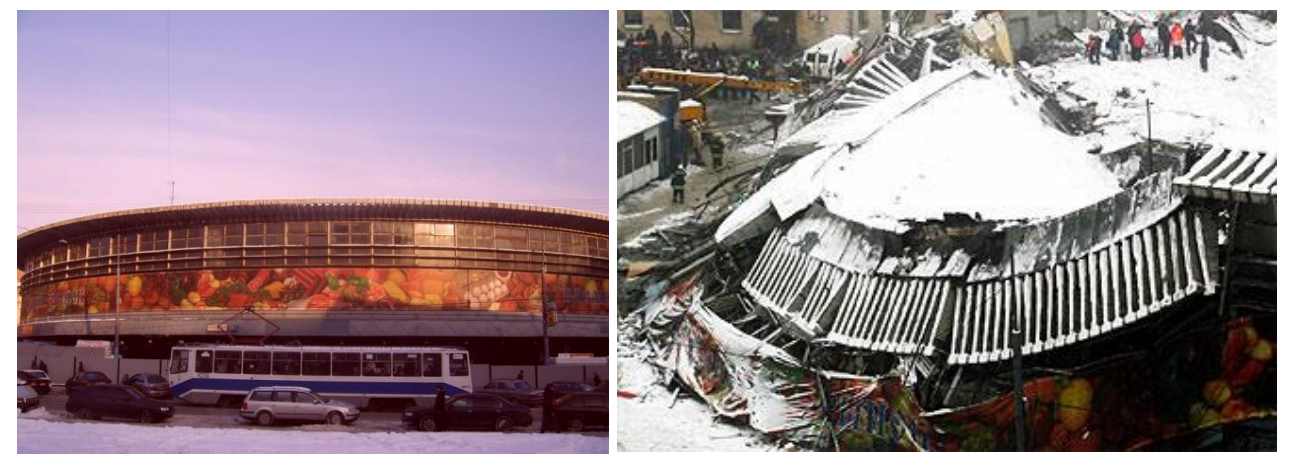

Fig. 2. Baumansky market before collapse, Moscow, Russia.

Fig. 3. Baumansky market after collapse, Moscow, Russia.

In this regard, continuous monitoring of the state of main load-bearing structures must be also carried out, especially since technical equipment is developed enough. In this case, monitoring should be understood as a system of technically and economically viable observations of impact factors, resistance to this effect and/or other integral indicators that determine the operability and specified reliability of a building or structure. It should be carried out with a period, in which the probability of an adverse event or manifestations of its consequences is negligible. [25-28]. 


\section{Materials and methods}

A huge number of studies is devoted to monitoring as a system of periodic observations of the technical condition of building structures. The main requirements for its implementation are set out in the regulatory documentation, in particular, in [GOST 31937-2011]. The literature also contains publications devoted specifically to the designing of monitoring systems [1-24] and defining some requirements for them. An example of designing such monitoring system is shown in Fig. 4. The process of parametric building planning can be described using BIM-technologies (Building Information Modeling), which is shared by architects, planners, cost designers, as well as operators when developing projects in the field of object management. Projects can be planned and deployed faster and more efficiently. Completed changes are available instantly to all participants.

The presence of sophisticated structural elements, which are in a complex multiparameter interaction both between themselves and with the environment, determines high requirements for the quality of design and construction, and is also inevitably associated with the possibility of defects at the operational stage.

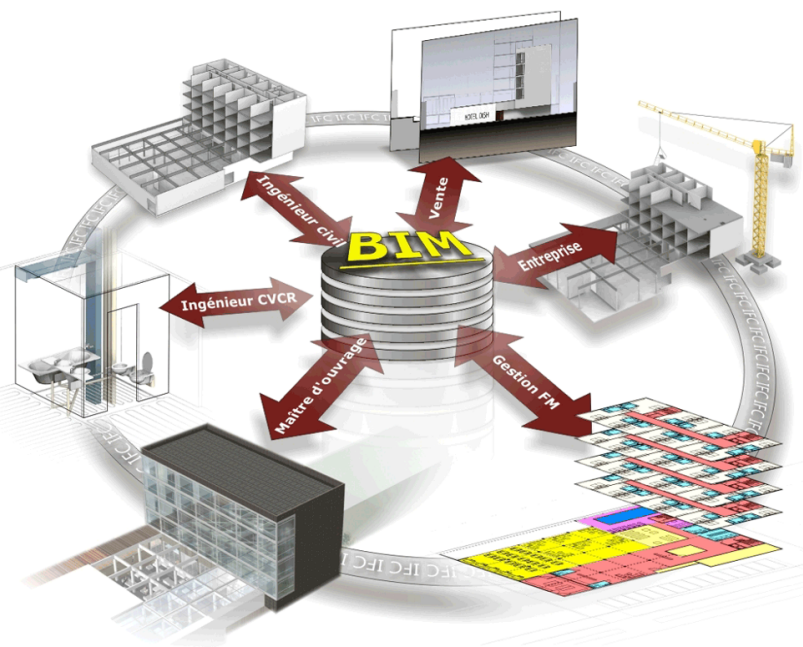

Fig. 4. Building Information Modelling(BIM).

The complexity of designing the analytical models is illustrated by the analysis of existing loads, which largely characterize the general stress-strain state of the structure. All current loads are conditionally divided into static and re-static (periodic). Static loads can lead to structural failure in the following cases:

- mismatch of operational loads with design ones;

- the presence of raw manufacturing defects in the design.

Periodic loads cause the development of local stress-strain areas with a high level of stress. These sections are grouped in the zone of geometric concentrators and other irregularities. Such loads lead to the occurrence or intensification of defects, change the design position of the structure.

According to the duration of the impact, the loads acting on buildings and structures can be classified as permanent and temporary, as well as super loads (Table 1).

Taking into account the variety of factors affecting the technical condition of building structures, and the complexity of their mathematical modelling, it becomes obvious that they cannot be fully taken into account in the used mathematical models. 
In addition to this, it should be emphasized that building materials combined in structures have different aging rates; there is a statistical variation in the characteristics of base soils and building construction materials.

The first problem in designing monitoring systems is the question of what to control. Without dwelling on the totality of engineering goals in construction, we only touch upon the goals associated with force impacts, i.e., supporting structures, such as the following:

- comparing the obtained state parameters of the controlled structures with standardized parameters defined in the project, or in regulatory documents;

- drawing up a conclusion on the current technical condition of the monitoring object and forecast for changes in the technical condition for the near future;

- controlling the compliance of the load parameters and the impact on the structures with the adopted design values or values indicated in the current regulatory documents;

- ensuring the safe functioning of load-bearing structures during the construction of buildings and structures, as well as during their operation; taking, if necessary, timely and adequate measures to strengthen the load-bearing structures.

Table 1. Load types.

\begin{tabular}{|l|l|l|}
\hline Load type & $\begin{array}{c}\text { Exposure } \\
\text { time }\end{array}$ & \multicolumn{1}{c|}{ Origin sources and nature of manifestation } \\
\hline Constant & Constant & $\begin{array}{l}\text { The weight of the structure, including the weight of the supporting } \\
\text { and enclosing building structures; soil weight and pressure }\end{array}$ \\
\hline \multirow{3}{*}{ Temporary } & Temporary & $\begin{array}{l}\text { Weight of temporary partitions; weight of stationary equipment, } \\
\text { tanks, pipelines with fittings; weight of liquids and solids filling the } \\
\text { equipment; pressure of gases, liquids and bulk solids in tanks and } \\
\text { pipelines; loads from stored materials and shelving equipment; } \\
\text { temperature, climatic effects due to changes in humidity, shrinkage } \\
\text { and creep of materials }\end{array}$ \\
\cline { 2 - 4 } & Short term & $\begin{array}{l}\text { Loads of equipment used during commissioning; loads from mobile } \\
\text { handling equipment: loaders, telphers, elevators; wind loads; ice and } \\
\text { snow loads }\end{array}$ \\
\hline Super & Short term & $\begin{array}{l}\text { Seismic explosive effects; impacts caused by deformations of the } \\
\text { base associated with a fundamental change in the structure of the soil; } \\
\text { loads caused by a sharp disruption of the technological process }\end{array}$ \\
\hline
\end{tabular}

The work scope on monitoring the load-bearing structures of buildings and constructions is determined by the Program, which includes systems for measuring and analyzing the stress-strain state of load-bearing structures.

Instrumental monitoring of building structures is based on considering loads and measuring deformations in the structures of foundations and above-ground parts, using geodetic, seismic, vibration, acoustic and other methods.

During the monitoring work, the following aspects should be systematically observed:

- deformations of individual structures;

- deformations of individual joints;

- general deformations of the building.

It is necessary to provide and ensure the stability of the observation system and the parameters of the measuring devices when conducting long-term observations, for example, in case of environmental changes (temperature, humidity, etc.) Deformations should be measured when observing large-span structures during decentering or removing the supports.

It is necessary to record the appearance and condition of cracks (direction, length and magnitude of opening) when observing the state of load-bearing concrete and stone structures during their erection. It is necessary to conduct geodetic monitoring of foundation deformations, building rolls and deflections of foundation mattresses, floors and 
coatings in order to early diagnose the technical condition of especially critical assemblies and structures and the localization of places of change in the stress-strain state. Instrumental monitoring in automatic or automated mode should also be conducted.

In order to detect changes in the stress-strain state of structures, automatic and automated control means must be installed during the construction of a building or structure. Subsequently, these controls can be used when monitoring a building or structure during operation.

In the case when critical changes in the stress-strain state of structures or joints are detected, the zones should be inspected using instrumental methods and the state of the entire building analyzed. Based on these results, conclusions about the technical condition of the structures are drawn, the reasons for the change in their stress-strain state are determined as well as the need for measures regarding restoration or strengthening of structures.

Instrumental systems should be used for monitoring the status of structures in the design position. These systems are based on strain measurements at various distinguished points of the structures using domestic and foreign magnetoelastic and string sensors, piestic dynamometers; voltage converters; deflection meters; fiber optic sensors and other devices.

Technical diagnostics of building structures includes the search for defects, measurement and control of diagnostic signs, analysis and processing of measurements and control. Diagnostics begins with a general examination of buildings and structures and their condition monitoring.

It is necessary to identify the construction design of foundations when inspecting buildings. Particular attention should be paid to lightweight and mixed masonry. When identifying the foundations of such a design, the boundaries of the bearing sections and the non-bearing filling should be determined. The construction design of foundations and basement walls can be determined by means of masonry sounding. During the general inspection of the columns, it is necessary to determine their cross sections and the detected deformations (deviation from the vertical, bend, displacement of the joints), fix and measure the width of the crack opening. When inspecting metal columns, particular attention should be paid to the corrosion damage, mainly at the floor level of the first floor or basement, as well as to general geometric shape of the columns and their compliance with the design position. Local deflections, dents and other mechanical damage to chords, lattice elements, mainly in the lower part of metal columns, as well as to erection joints of columns and the quality of welds are recorded. The columns of the building are checked for the following aspects during inspection: design compliance of the interface nodes of the columns with adjacent structures; the presence of all elements of the bracing structures according to the design; general curvature of branches, connections and elements of the connecting lattice of metal columns; local mechanical damage to the bracings. The condition of the connections of bracings to the columns and the butt joints of the braced framings are monitored. For the reinforced concrete columns, the junctions between the beams and the columns are carefully examined during inspections, as well as the verticality of columns and beams and their mutual bracing on the abutments.

The performed calculations allow selecting the optimal ratio in the design, regarding both material and the geometry. In this sense, the construction becomes fully-stressed. It is almost impossible to control all structures at the present time. What is to be done? The key to solving this problem is probably controlling the most stressed zones. Such certainly exist in the structure, at least due to the fact that the reinforcement of concrete structures is the same for a certain area with variable loads within, and the corresponding stresses. Areas with increased stress in relation to adjacent areas can be distinguished in any structure, as well as in any structural element. And this is the more noticeable, the further the designer departed from strength uniformity for the sake of constructible considerations. It should be 
noted that particularly "constructible" considerations often prove to be economically more expedient.

One supposing was made for selecting the installation locations of sensitive elements that allow controlling mechanical stresses, which in fact is the main indicator of structure condition, studied at the design stage of the object.

The matching of calculated and actual values shows the correctness of the calculations and the well-being of the structures, a significant difference requires taking corresponding measures to explain the reasons for the mismatch, analyze them and make a technically adequate solution for this particular situation. There can be many reasons for the mismatch, for example, inaccuracies made during engineering and geological surveys or their interpretation; errors in the project; technological features of the construction of structures, also expressed in inability to ensure the quality of materials. In addition to above mentioned reasons, there may be geotechnical reasons noted in [29], namely the impossibility of determining the natural stresses in the soil mass of the base, which significantly affect the characteristics of the foundations, their settlement and deformation. Flaws in the monitoring systems themselves should also be noted, which are caused by the interpretation of the data being learned. Thus, for example, the stress-strain state of structures can be determined by installing strain gauges (electrical, fiber optic, string or any other), determining deflections by geodetic methods or by installing displacement sensors. It can also be determined by analyzing the acoustic emission signals, measuring the angle of inclination of the observed structure, etc. Each of the above mentioned methods requires its own calibration, but in this case various values of the parameter of interest can be also obtained, for example, the values of mechanical stresses in the structure.

\section{Research results}

Let us more carefully consider one of the above mentioned statements, namely, the need to control mechanical stresses in the structure or pressure in the soil mass, including the foundation-soil contact.

Firstly, are the measured stresses large or small? The answer to this question will be given by comparing them with the limiting or permissible values for a given material in the particular construction. Therefore, not only the impact must be controlled, but also the resistance to the impact. This simple truth was stated by leading Soviet scientists Rzhanitsin and Bolotin back in the sixties of the last century [30-31]. However, in scientific researches devoted to monitoring, only the effect is considered and practically no mention is made of resistance to this effect. A structure has been installed on the concrete block, the section of the block and the current load is continuously monitored, they remain unchanging. However, after two years, the structure collapses. What was the reason? The answer is simple, the frost resistance of concrete was insufficient, the concrete was degraded, i.e. crumbled. Stresses remained unchanged, but the ratio of the impact and resistance to this effect changed significantly due to a sharp decrease in the latter.

Secondly, stresses having $\left[\mathrm{N} / \mathrm{m}^{2}\right]$ quality dimension are not one of the seven basic units of the SI system adopted by the 11th general conference on measures and weights (1960), where the main ones are as follows: units of time - second; lengths - meter; masses kilogram; current strength - amperes; temperature - kelvin; the amount of substance mole; light forces - candela. Stresses relate to many derived units formed from basic units using formulas and equations that relate the corresponding quantities. Thus, stresses cannot be measured directly, only indirectly, which causes additional errors that arise when measuring the main quantities that make up the derivative.

The second monitoring issue is selecting the controls and the measurement base. 
The use of specialized sensors is advisable for solving the problems of monitoring engineering constructions, buildings and structures. For the certain joints of the structure, the sensors should be distributed according to the measured parameters. A competent solution to the problem of monitoring structures will be the integrated use of the main groups of measuring devices, since this gives a really complete view of the state of the main structural components. Domestic and foreign industry produces a wide range of controls, such as the following:

1. Extensometers. They are used to measure stresses in materials. A good example is long span metal beam. In addition to deflections, the beam is also subject to twisting. Extensometers should be installed in the middle between the beam supports. In such places, where the material works only due to its properties, there is a probability of obtaining proper data. Visually, the beam does not yet take the form of a spiral, but material shifts and overstressings are already starting. The extensometer mounted on two fixed points measures the smallest change in distance between them;

2. Inclinators. These are sensors that measure the deviation of a controlled object from a vertical axis or, in other words, the inclination angle that is relative to the direction of the Earth's gravitational field vector. A classic example is the use of inclinometers for bearing columns, support poles.

3. Accelerometers. They are used to measure accelerations. From a constructive point of view, vibration characteristics of the material, where the accelerometer is installed, are important. A classic example is the large spans of the bridge and its cables.

In addition, instruments that measure the speed and other parameters of the passage of an ultrasonic wave in various media are used.

Let us consider extensometers. The electric ones are used to control the load-bearing structures (Fig. 5). The appearance of cracks causes an abrupt increase in the readings of the extensometer, which usually precedes the destruction of the material. Vibrating wire extensometers (Fig. 6) are used to control deformation in steel or reinforced concrete and massive concrete structures. Weld wire extensometers are designed to be welded by arc welding to steel structures, such as lining tunnels, piles and bridges. The meters are equipped with mounting units. Embedded wire extensometers are inserted directly in concrete for measuring deformations in piles, foundations, dams, tunnels lining, etc. Optical amplitude extensometers detect changes in the transmitted light flux through a divided fiber. This is based on the fixation of reflected scattering or on changing the step of the diffraction grating, embedded in the fiber when it is stretched or compressed.

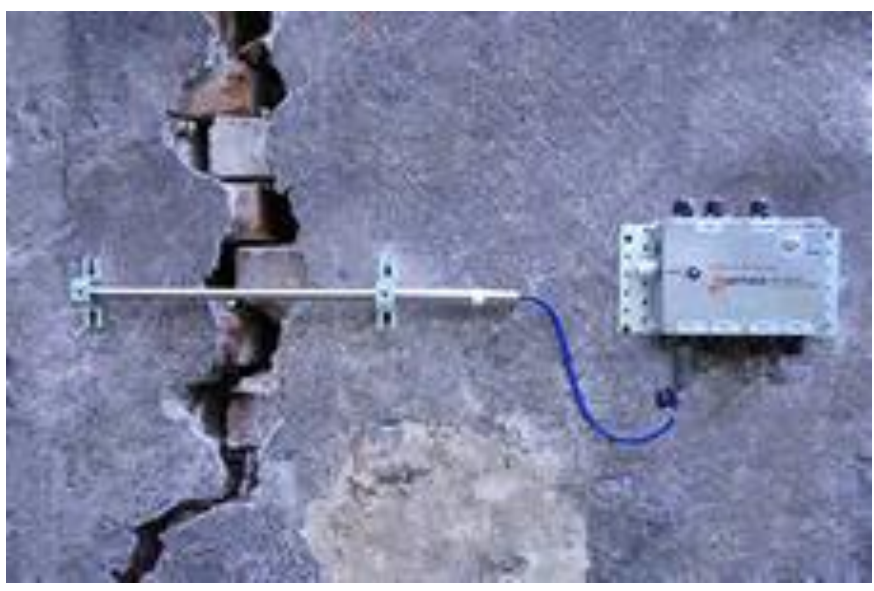

Fig. 5. Electric extensometer. 


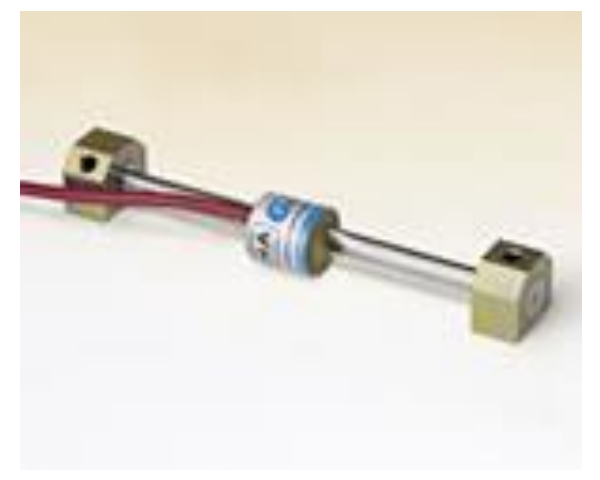

Fig. 6. Wire extensometer.

Means of control also differ on the basis of measurements, i.e., on the zone length of the structure in which measurements are made. It is necessary to clearly understand the purpose of the measurement in order to select the base length. If changes in the level of stresses need to be measured in a structure with a sharply changing geometry, which is made of a material with stable and well-studied properties, then it is necessary to use extensometers with an extremely short base. If the properties of the material, such as the elastic modulus $\mathrm{E}$, change within the material volume and acquire values of $E_{1} ; E_{2} \ldots E_{i}$, then a short-base extensometer will not allow obtaining the data about the stresses acting in the considered zone. Let us assume that the relative strain $\varepsilon$ was measured absolutely accurately. What are the $\sigma$ stresses in this case? Is their value $\sigma_{1}=E_{1} \varepsilon$, or $\sigma_{2}=E_{2} \varepsilon$, or $\sigma_{\mathrm{i}}=E_{\mathrm{i}} \varepsilon$ ? Concrete, as well as steel, is a multicomponent material. The difference is that the grain size of the steel is from 10 to 100 micrometers, while the concrete aggregate can have a size of up to 100 or more millimeters. The difference in size is three orders of magnitude. In mechanical engineering, extensometers with a base size between 5 and $20 \mathrm{~mm}$ have proven themselves well. From these positions, the base of extensometers for concrete should be from 5 to 20 meters. Opponents can rightly notice that GOST 10180-90 "Betony i metody opredeleniia prochnosti po kontrolnym obraztsam" involves testing cubes with a rib of $100 \mathrm{~mm}$. Therefore, the base length of the extensomter should also be $100 \mathrm{~mm}$. However, the specified GOST also provides for cubes with an edge of $300 \mathrm{~mm}$ during compression tests, as well as "eights" when determining axial tensile strength with an active zone of 300 to $600 \mathrm{~mm}$. In this case, a series test is provided. With a variation coefficient of the studied properties (strength in our case) of more than $8 \%$, the required number of samples in a series is at least 6 (note that the variation coefficient for modern concrete plants is much larger even in one batch, usually it is assumed to be $13.5 \%$ ). The number of samples in the series depends on the shape and ranges from 3 to 4 . So, 18 to 24 samples with an edge from 100 to 300 are to be tested. The length of the series of such samples is from 1.8 to 7.2 meters. The opponent will rightly note that all this relates to strength, and not to the modulus of elasticity. Then we will refer to the studies of the winners of the USSR State Prize V.N. Baykov and E. E. Sigalov, in particular, to the study [32], where an almost direct correlation between the elastic modulus and the concrete grade is indicated. By the way, the elasticity modulus of steel also depends on its strength.

\section{Discussion}

Let us return to the first question, in order to avoid errors of this kind, the controlled parameters properly selected. In other words, it is better to monitor the parameters measured by the basic units of the SI system. According to this logic, we will conclude that 
the smallest measurement errors will occur when monitoring dimensionless quantities, for example, acoustic emission. Monitoring the basic values of the SI system should be put in the second place from this point of view, in particular the geometrical characteristics of the object, measured in meters, i.e., geodetic monitoring. Monitoring the simplest derivatives of the SI system, such as the oscillation frequency measured in $[1 / \mathrm{s}]$ will be the third position. Monitoring such quantities as stresses with a very complex dimension $\left[\mathrm{Pa}=\mathrm{N} / \mathrm{m}^{2}\right.$ $\left.=\left(\mathrm{kg} / \mathrm{m} / \mathrm{s}^{2}\right) / \mathrm{m}^{2}=\mathrm{kg} / \mathrm{m} \times \mathrm{s}^{2}\right]$ can be only put in the fourth position.

Let us approach the issue of the extensometer length in terms of mathematical statistics. Assuming that the length of the extensometer $\tau$ is much greater than the length of the section $\ell$, within which the material properties remain unchanged, $\tau=n \times \ell$, where $n$ is the number of sections within the extensometer length. The relative elongation of each section at a constant stress acting in the studied zone, is inversely proportional to the elastic modulus $E_{\mathrm{i}}$ in this section. Therefore, the value inversely proportional to the elastic modulus is taken as the characteristic of the material in this section.

Let us determine the variance $D$ of this parameter, and hence the material properties along the extensometer, considering that the variance of the sum of independent random variables is equal to the sum of the variances, and the constant factor is taken out of the dispersion sign squared.

$D\left(\frac{1}{\mathrm{E}_{e f}}\right)=D\left(\frac{1}{n} \sum_{i=1}^{n} \frac{1}{\mathrm{E}_{i}}\right)=\frac{1}{n^{2}} D\left(\sum_{i=1}^{n} \frac{1}{\mathrm{E}_{i}}\right)=\frac{1}{n^{2}} \sum_{i=1}^{n} D\left(\frac{1}{\mathrm{E}_{i}}\right)=\frac{1}{n^{2}} \sum_{i=1}^{n} D_{o}=$
$\frac{1}{n^{2}} n D_{o}=\frac{D_{o}}{n}$

where $E_{e f}$ is the effective modulus of elasticity, $D_{\mathrm{o}}$ is the dispersion of the properties of a given material over a section length $\ell$.

According to this, the standard deviation defined as the square root of the variance for extensometer, which is $\mathrm{n}$ times longer than the basic one, will be $\sqrt{n}$ less than the root mean square ratio of the basic extensometer. The same applies to the variation coefficient. The variation coefficient of the readings of a two hundred millimeter extensometer will be more than three times greater than the variation coefficient of a two meter extensometer. Consequently, extensometers with a larger base are preferred for studying the multicomponent structurally heterogeneous materials.

\section{Conclusions}

On the basis of the foregoing, the following conclusions that are consistent with the goals can be drawn.

The main goal of monitoring building structures is to ensure their technical safety at the stages of construction and operation.

In order solve this problem, the designing of monitoring systems should be based on recording the parameter of interest using sensors based on various physical principles. Moreover, it is necessary to monitor both the factor affecting the object of observation, and the factor of resistance to this effect (tracking some integral indicator reflecting their ratio is permissible). The safety of the structure is determined not only by the ratio of the average values of the impact and resistance indicators, but also by the statistical characteristics of the measured values, at least by the standard deviation. The absolute values of the measured quantities and their statistical characteristics, determined during single or periodic observations, provide information on their ratio without taking into account the accumulated damage in the material of structures. The degree of damage accumulation can only be determined during continuous (quasi-continuous) observations that record all, without exception, changes in the magnitude of the impact in a given monitoring time 
interval. The obtained indicators should be possible to compare not only with their limit values, but also the rate of change should be able to calculate, which will allow determining the time interval for further incident free operation.

\section{References}

1. N.A. Makhutov, Zavodskaia laboratoriia. Diagnostika materialov 77(12), 3-4 (2011)

2. V.O. Almazov, A.N. Klimov, Vestnik MGSU 2-1, 116-120 (2011)

3. E.Iu. Kulikova, Gornyi informatsionno-analiticheskii biulleten (nauchno-tekhnicheskii zhurnal 7, 152-157 (2013)

4. K.Iu. Zhigalov, Fundamentalnye issledovaniia 9-7, 1436-1440 (2014)

5. A.G. Tamrazian, Stroitelnye materialy, oborudovanie, tekhnologii XXI veka 3(170), 19-21 (2013)

6. L.N. Chernyshov, V.A. Stolbova, Nauchnyi zhurnal stroitelstva i arkhitektury 4, 67-76 (2010)

7. A.M. Danilov, I.A. Garkina, E.A. Budylina, I.N. Garkin, Otraslevye aspekty tekhnicheskikh nauk 10(34), 3-6 (2013)

8. V.S. Soldatenko, V.N. Kharin, Inzhenerno-stroitelnyi zhurnal 2(46), 47-57 (2014)

9. K.Iu. Dolinskii, A.A. Lykov, V.B. Sokolov, V.A. Sokolov, G.V. Osadchii, Promyshlennoe i grazhdanskoe stroitelstvo 11, 34-35 (2010)

10. Iu.E. Fedoseev, E.A. Egorchenkova, Inzhenernye izyskaniia 12, $50-57$ (2010)

11. E.A. Moiseichik, E.K. Moiseichik, P.A. Atrushkevich, Vestnik BelorusskoRossiiskogo universiteta 4, 135-146 (2010)

12. M.V. Emelianov, Nauchnoe obozrenie 10-2, 24-27 (2015)

13. V.F. Mushchanov, E.V. Gorokhov, Obsledovanie zdanii i sooruzhenii: problemy i puti ikh resheniia Materialy VI mezhdunarodnoi nauchno-prakticheskoi konferentsii, 124138 (2015)

14. E.P. Zolotukhin, A.P. Kuzmenko, V.D. Neskorodev, A.V. Komarov, V.S. Saburov, D.B. Korolenko, Seismicheskie pribory 53(2), 23-36 (2017)

15. A.P. Lediaev, A.N. Konkov, A.L. Novikov, D.A. Soloviev, Promyishlennoe i grazhdanskoe stroitelstvo 12, 83-86 (2014)

16. A.V. Demenev, Collection: Perspective research in science: theory and practice The Collection of Scholarly Papers, 195-199 (2016)

17. A.V. Korgin, M.V. Emelianov, Promyshlennoe i grazhdanskoe stroitelstvo 3, 32-34 (2011)

18. B. Chen, Y.L. Xu, X. Zhao, Smart Structures and Systems 6(7), 811-833 (2010)

19. A.R. Emanov, V.N. Maksimenko, L.A. Sklyarov, Collection: 2007 International Forum on Strategic Technology, IFOST Ulaanbaatar, 104-108 (2007)

20. S.V. Usanov, V.I.Ruchkin, O.D. Zheltysheva, Journal of Mining Science 51(4), 724729 (2015)

21. A. Cataldo, E. De Benedetto, G. Cannazza, E. Piuzzi, Collection: XXI IMEKO World Congress "Measurement in Research and Industry" 21 (2015)

22. Xiaoyan Zhao, Hongnan Li, De Du, Jinglong Wang, Collection: Sensors and Smart Structures Technologies for Civil, Mechanical, and Aerospace Systems, 693208-8 (2008) 
23. A. Ginzburg, S. Kachanov, International Journal of Applied Engineering Research 11(3), 1660-1665 (2016)

24. O.E. Sysoev, D. Li, W. Du, H. Wang, Shenyang Jianzhu Gongcheng Xueyuan Xuebao (Ziran Kexue Ban) 27(6), 1099-1102 (2011)

25. T. Simankina, I. Kibireva, A.Mottaeva, M. Gusarova, Advances in Intelligent Systems and Computing. 983, pp. 138-145, (2019) https://doi.org/10.1007/978-3-030-19868$\underline{8} 13$

26. I.V. Rubtsov, A.V. Kukhta, Krovelnye i izoliatsionnye materialy 6, 44-45 (2007)

27. I.V. Rubtsov, Stroitelnye materialy, oborudovanie, tekhnologii XXI veka 10, $42-44$ (2007)

28. I.V. Rubtsov, Stroitelnye materialy oborudovanie i tekhnologii KhKhI veka 6(101) (2007)

29. A.L. Kryzhanovskii, O.I. Rubtsov, Vestnik MGSU, Mekhanika gruntov. Osnovaniia i fundamenty 1 (2006)

30. D.A. Gura, I.G. Markovskii, B.A. Hahuk, S.K. Pshidatok, IOP Conference Series: Materials Science and Engineering 698(4), 044014 (2019). DOI: 10.1088/1757899X/698/4/044014

31. A.S. Gorshkov, N.I. Vatin. Magazine of Civil Engineering. 2013. 40(5). Pp. 5-19. DOI:10.5862/MCE.40.1.

32. V.N. Baikov, E.E. Sigalov, Zhelezobetonnye konstruktsii. Obshchii kurs (Stroiizdat, Moscow, 1991) 